\title{
Clinical Presentation of Ovarian Tumors
}

\author{
Qamarunissa Muhabat' ${ }^{1}$, Fakharunissa Waheed ${ }^{2}$, Waqarunissa ${ }^{3}$, Nigar Jabeen ${ }^{4}$ \\ ${ }^{1}$ Department of Obstetrics \& Gynecology, Aga Khan Maternity \& Child Care Hospital, Hyderabad Sindh, \\ Pakistan \\ ${ }^{2}$ Department of Obstetrics \& Gynecology, Indus Tando M. Khan, Hyderabad Sindh, Pakistan \\ ${ }^{3}$ Department of Obstetrics \&Gynecology, Isra University Hospital, Hyderabad Sindh, Pakistan \\ ${ }^{4}$ Department of Obstetrics \& Gynecology, Aga khan Maternity \& Child Care Hospital, Hyderabad Sindh, Pakistan \\ Email: qamarunissanoonari@yahoo.com
}

Received 9 February 2016; accepted 14 March 2016; published 17 March 2016

Copyright () 2016 by authors and Scientific Research Publishing Inc.

This work is licensed under the Creative Commons Attribution International License (CC BY).

http://creativecommons.org/licenses/by/4.0/

(c) (i) Open Access

\begin{abstract}
Ovarian malignancy is a serious disease affecting women of all ages, more so above 50 years, and they are still difficult to treat, partly because no truly effective therapy has yet been developed although presentation is often vague and non-specific, the symptoms are definitely present. It is important to recognize the symptoms so far, there is no test yet available, which is truly specific and suitable for screening and early detection of epithelial ovarian carcinoma. So, it is concluded that for prognosis and patient survival, early detection and treatment is mandatory.
\end{abstract}

\section{Keywords}

\section{Ovaries, Ovarian Tumor, Clinical Presentation}

\section{Introduction}

Ovarian tumor is one of the most common gynecological tumors seen in female although there are different types of ovarian tumor but epithelial ovarian cancer is the fifth most common cause of cancer death in women [1]. In Pakistan, it is the $2^{\text {nd }}$ most common cause of death in women malignancies after breast tumor [2].

It is often called the "silent killer" because the disease is not often detected until it reaches an advance stage. Due to its anatomical location, such ovarian tumors may remain unnoticed for a long period of time [3] [4]. Ovarian cancer usually affects the age of 65 years or older more frequently than younger women [1], they are not always malignant, but, the incidence of malignancy is about $15 \%-25 \%$ in different parts of the world [5]. The incidence is high in North America and Europe as compared to Japanese [6]. These tumors behave in diverse ways and are generally not detected until they get large size [7]. Ovarian tumors may be cystic or solid in consistency. Most of the benign tumors are cystic but $80 \%$ of solid ovarian tumors are malignant [3] [8]. 
There are a number of risk factors associated with their origin. None of these has been yet proved except for age and parity [9]. The relative risk for ovarian malignancy increases significantly after the age of 40 years [10]. An early menarche and late menopause are associated with an increased risk [11]. Use of oral contraceptive is associated with a reduced risk of benign ovarian neoplasma [12]. Common symptoms include abdominal distension, abdominal and pelvic pain, and dyspepsia and also increased the frequency of urine [13]. Family history of ovarian and breast cancer has strong link and considers as major risk factor for ovarian cancer [14] [15]. One theory is that ovarian carcinoma arises from endometriosis; it is the presence of endometrial tissue rather than uterus [16].

\section{Data Collection Procedure}

Patients who had fulfilled the inclusion criteria were included in study; coming from OPD then informed consent was taken from patient. Details of the patient's symptoms were recorded on pre-designed Performa. Demographic profile including age, address, and parity was noted. A detail of symptoms was asked by researcher.

Symptoms which has been asked from patients include abdominal pain, abdominal mass and abdominal enlargement. Details of gastrointestinal symptoms like nausea, vomiting and urinary symptoms like increase in urinary frequency were asked. Constitutional symptoms including weight loss was asked. Then diagnosis is confirmed by ultrasound or laparotomy and histopathology.

\section{Data Analysis}

All the information has been entered in the proforma attached as annexure by the researcher and analyzed by using SPSS version 15.0.

\section{Results}

This case series study was conducted in the department of Obstetrics \& Gynecology, Isra University Hospital, to determine the frequency of various clinical presentations of ovarian tumors by age and stage of disease.

Total 97 women with various clinical presentation of ovarian tumor were enrolled in this study based on inclusion \& exclusion criteria. All the women were distributed and results are shown in the systemic order.

In my study majority of women i.e. 37 (38.1\%) belonged to age group >60 years while 17 (17.5\%) belonged to $<30$ years (Table 1). Regarding the duration of symptoms i.e. 18 (18.6\%) women has symptoms of less than 6 months while 42 (43.3\%) women had symptoms for more than 1 year (Table 2). Table 3 shows that majority of women i.e. 47 (48.5\%) were nullipara while 21 (21.6\%) were multipara. In my study majority of women i.e. $43(44.3 \%)$ had abdominal mass \& 19 (19.6\%) had increased urinary frequency, while 19 (19.6\%) were

Table 1. Frequency of age groups of study participants $(n=97)$.

\begin{tabular}{ccc}
\hline Age group & Frequency & Percentage \\
\hline$<30$ years & 17 & $17.5 \%$ \\
$30-40$ years & 11 & $11.3 \%$ \\
$41-50$ years & 15 & $15.5 \%$ \\
$51-60$ years & 17 & $17.5 \%$ \\
$>60$ years & 37 & $38.1 \%$ \\
Total & 97 & $100.0 \%$ \\
\hline
\end{tabular}

Table 2. Duration of symptoms $(\mathrm{n}=97)$.

\begin{tabular}{ccc}
\hline Duration & Frequency & Percentage \\
\hline$<6$ months & 18 & $18.6 \%$ \\
6 months to 1 year & 37 & $38.1 \%$ \\
$>1$ year & 42 & $43.3 \%$ \\
Total & 97 & $100.0 \%$ \\
$<6$ months & 18 & $18.6 \%$ \\
6 months to 1 year & 37 & $38.1 \%$ \\
\hline
\end{tabular}


asymptomatic (Table 4). Table 5 shows the stage of ovarian tumor i.e. 77 (79.6\%) patients had benign tumor while 20 (20.6\%) patients had malignant ovarian tumor.

\section{Discussion}

Early diagnosis of ovarian cancer is challenge to gynecologist, mainly due to the fact that symptoms in early disease are vague and non-specific. Several studies have shown that women with ovarian cancer experience abdominal, GIT \& constitutional symptoms, more as compared to those with benign tumors [17] [18].

In my study, $19.6 \%$ patients were asymptomatic while the result of study conducted by Wasim T. shows that $11 \%$ patients were asymptomatic [3]. Ovarian cancer is common in low parity \& infertile women probably due to incessant ovulation theory. In my study, $48.5 \%$ women who had ovarian tumor were nullipara while $21 \%$ multipara. However in study conducted by khan I, at KEMU/Lady Willington hospital, 58.15\% women who had ovarian tumor were multipara [19]. In another population based case control study, Titus Ernstaff et al. found that risk of ovarian tumors was higher in multiparous [20], a woman which is comparable to results of my study.

Another study conducted by Naheed A. Malik shows the percentage of weight loss is $4 \%$, these findings are similar to the present study [5]. Delay in presentation is one of the big dilemmas with ovarian cancer \& is responsible for high mortality associated with disease. Similar delays have been reported in other studies [21] [22].

In my study, 43\% presented with ovarian tumor after 1 year of development of symptoms reason of delay were non-specific symptoms, inadequate health care system, omission of pelvic examination at presentation,

Table 3. Parity of women $(n=97)$.

\begin{tabular}{ccc}
\hline Parity & Frequency & Percentage \\
\hline Nullipara & 47 & $48.5 \%$ \\
Primipara & 29 & $29.9 \%$ \\
Multipara & 21 & $21.6 \%$ \\
Total & 97 & $100.0 \%$ \\
\hline
\end{tabular}

Table 4. Frequency of various symptoms of study participants $(n=97)$.

\begin{tabular}{ccc}
\hline Symptoms & Frequency & Percentage \\
\hline Asymptomatic & 19 & $19.6 \%$ \\
Abdominal mass & 43 & $44.3 \%$ \\
Increased urinary frequency & 19 & $19.6 \%$ \\
Nausea & 10 & $10.3 \%$ \\
Vomiting & 2 & $2.1 \%$ \\
Weight loss & 4 & $4.1 \%$ \\
Total & 97 & $100.0 \%$ \\
\hline
\end{tabular}

Table 5. Stage of ovarian tumor $(n=97)$.

\begin{tabular}{ccc}
\hline Stage & Frequency & Percentage \\
Benign & 77 & $79.3 \%$ \\
Malignant & 20 & $20.6 \%$ \\
Malignant stage I & 7 & $7.2 \%$ \\
Malignant stage II & 5 & $5.1 \%$ \\
Malignant stage III & 3 & $3.09 \%$ \\
Malignant stage IV & 5 & $5.1 \%$
\end{tabular}


illiteracy \& poverty.

\section{Conclusion}

Ovarian tumor can affect peri- and postmenopausal women. The peak incidence is above 50 years of age. The women having history of malignancy in family should screen regularly specially in old age. So, it is concluded that for prognosis and patient survival, early detection and treatment is mandatory, which may reduce mortality. There is need to increase awareness of population. Abdominal and pelvic bimanual examination should be carried out in every patient presenting with gynecological problem and appropriate investigations in post menopausal women in early period to diagnose the disease at an early stage.

\section{References}

[1] Mandiac, A., Nincic, D. and Vujkov, T. (2003) Ovarian Epithelial Carcinoma; a Malignant Disease Sparing No Age Group. Medicinski pregled, 56,157-61. http://dx.doi.org/10.2298/MPNS0304157M

[2] Saler, E., Eliyahaus, S., Leleg, D. and Tsabari, A. (1994) Laparoscopic Management of Adenexal Cystic Mass in Post Memopausal Women. Obstetrics \& Gynecology, 83, 594-596. http://dx.doi.org/10.1097/00006250-199404000-00018

[3] Wasim, T., Majrooh, A. and Siddiq, S. (2009) Comparison of Clinical Presentation of Benign and Malignant Ovarian Tumors. Journal of Allama Iqbal Medical College, 59, 18-21. http://dx.doi.org/10.1016/s0020-7292(09)62602-3

[4] Shaikh, N.A., Hashmi, F. and Samoo, R.P. (2007) Pattern of Ovarian Tumor: Report of 15 Years’ Experience at Liaquat University Jamshoro. Journal of Liaquat University of Medical \& Health Sciences, 6, 14.

[5] Naheed, I., Malik, S. and Shaukat, M.S. (2001) Review of Ovarian Tumors. Journal of Rawalpindi Medical College (JRMC), 7, 180-182.

[6] La Vacchia, C. (2001) Epidemiology of Ovarian Cancer: A Summary Review. EURT Cancer Review, 10, 125-129. http://dx.doi.org/10.1097/00008469-200104000-00002

[7] Zafar, F.A., Fazil, A., Asifa, A., Karim, A. and Akmal, N. (2005) Clinical Manifestations of Benign Ovarian Tumors. Journal of Liaquat University of Medical \& Health Sciences (JLUMHS), 11, 258-259.

[8] Chohan, A. (2005) Benign Diseases of Ovary. In: Chohan, A., Fundamentals of Gynecolgy, Mar Publication, Lahore, 281.

[9] Greenlee, R.T., Hill Harmone, M.B., Murray, T. and Theen, M. (2001) Cancer Statistic 2001. CA: A Cancer Journal for Clinicians, 51, 15. http://dx.doi.org/10.3322/canjclin.51.1.15

[10] Tay, S.K. and Tan, Y.Y. (1992) Risk Factors and a Risk Scoring System for the Prediction of Malignancy in Ovarian Cysts. Australian and New Zealand Journal of Obstetrics and Gynaecology, 32, 341-345. http://dx.doi.org/10.1111/j.1479-828X.1992.tb02848.x

[11] Gabra, H. (2007) Epithelial Ovarian Cancer. Dewhurst's Textbook of Obstetrics and Gynaecology. 7th Edition, WILEY-BlACKWELL, London, 625-635. http://dx.doi.org/10.1002/9780470753354.ch55

[12] Booth, M., Beral, V., Machonochie, N., Carpenter, L. and Scott, C. (1992) A Case Control Study of Benign Tumors. Journal of Epidemiology \& Community Health, 46, 528-531. http://dx.doi.org/10.1136/jech.46.5.528

[13] Goff, B.A., Mandel, L.S., Melancon, C.H. and Muntz, H.G. (2004) Frequency of Symptoms of Ovarian Cancer in Women Presenting to Primary Care Clinics. JAMA, 291, 2705-2712. http://dx.doi.org/10.1001/jama.291.22.2705

[14] Rufford, B.D., Jacobs, I.J. and Memon, U. (2007) Feasibility of Screening for Ovarian Cancer Using Symptoms as Selection Criteria. BJOG, 114, 59-64. http://dx.doi.org/10.1111/j.1471-0528.2006.01153.x

[15] Shen-Gunther, J., Mannel, R.S. (2002) Ascites as a Predicator of Ovarian Malignancy. Gynaecological Oncology, 87, 77-83. http://dx.doi.org/10.1006/gyno.2002.6800

[16] Ness, R.B. and Cottreau, C. (1999) Possible Role of Ovarian Epithelial Inflammation in Ovarian Cancer. Journal of the National Cancer Institute, 91, 1459-1467. http://dx.doi.org/10.1093/jnci/91.17.1459

[17] Boyle, P. and Ferlay, J. (2005) Cancer Incidence and Mortality in Europe, 2004. Annals of Oncology, 16, 481-488. http://dx.doi.org/10.1093/annonc/mdi098

[18] Yawn, B.P., Barrette, B.A. and Wollan, P.C. (2004) Ovarian Cancer: The Neglected Diagnosis. Mayo Clinic Proceedings, 79, 1277-1282. http://dx.doi.org/10.4065/79.10.1277

[19] Khan, I. and Shezadi, N. (2010) Prospective Study of Ovarian Tumors Clinical Pattern and Their Management at Lady Willingdon Hospital. Pakistan Journal of Medical and Health Science, 4, 159-162.

[20] Titus-Ernstoff, L., Perez, K., Cramer, D.W., Harlow, B.L., Baron, J.A. and Greenberg, E.R. (2001) Menstrual and Re- 
productive Factors in Relation to Ovarian Cancer Risk. British Journal of Cancer, 84, 714-721. http://dx.doi.org/10.1054/bjoc.2000.1596

[21] Olsen, C.M., Cnossen, J., Green, A.C. and Webb, P.M. (2007) Comparison of Symptoms and Presentation of Women with Benign, Low Malignant Potential and Invasive Ovarian Tumors. European Journal of Gynaecological Oncology, 28, 376-380.

[22] Diagnosis: Types of Tumor. http://ovariancancer.jhmi.edu/lmp.cfm 